\title{
Performance Analysis of Parabolic Trough Collector
}

\author{
Y. K. Nayak ${ }^{\# 1}$, U. K. Sinha ${ }^{\# 2}$, P. Kumar ${ }^{* 3}$, N.Kumar ${ }^{\# 4}$ \\ \#Electrical and Electronics Engineering Department, \\ National Institute of Technology, Jamshedpur, Jharkhand - 831014, India \\ 1ee512035@nitjsr.ac.in \\ 2uksinha.ee@nitjsr.ac.in \\ ${ }^{4}$ 2013pgphdee01@nitjsr.ac.in \\ *Mechanical Engineering Department, \\ National Institute of Technology Jamshedpur, Jharkhand - 831014, India \\ ${ }^{3}$ pkshmdme@gmail.com
}

\begin{abstract}
Performance evaluations of parabolic trough collector have been studied on the basis of mathematical analysis of various parameters. Mathematical expressions have been developed for the model to simulate the results of performance evaluation using $C++$ program. On the basis of simulated results, variation of efficiency, heat removal factor, outlet fluid temperature as a function of dimensionless insolation for fixed and variable radiative loss parameter and thermal loss parameter. Outlet fluid temperature as a function of mass flow rate for a fixed value of radiative and thermal loss parameters have been studied. The effect of thermal and radiative loss parameters have been studied for variation of the difference of outlet and inlet fluid temperatures against dimensionless insolation.
\end{abstract}

Keywords-Parabolic trough collector, Heat removal factor, Dimensionless insolation, Radiative and thermal loss parameters, Outlet and inlet fluid temperatures

\section{INTRODUCTION}

The authors describe the analytical approach to simulate the various parts of a solar thermal power plant. A simple $C++$ program, based on that mathematical model, can be built up to obtain statistical results under the particular conditions recognized by the user. The first part of the section analyses the conversion of solar to thermal energy as shown in Fig. 1. The system consists of a solar collector and a storage device that supply thermal energy to a load, which is input to the heat engine for the solar driven power generation. The most successful solar thermal development has been the linear SEGS plants developed and installed by LUZ International Limited between 1984 and 1990 located in California. Parabolic Trough Collector technology has established its capacity to drive a commercial power plant [1]. A variety of procedures to calculate the property of the operational behaviour of solar collectors can be found in the technical literature. Milton et al. [2] studied modeling the behaviour of a solar power plant with the parabolic linear collector is most essential as a design and optimization tool that can approach a variety of situation. Yebra et al. [3] developed the design of advanced control systems to optimize the general performance of parabolic trough collectors, solar plants with direct steam generation is today a high-priority line of research. They developed the guidelines for dynamic model and control system design for such type of plants. The experimental and predicted values were compared and discussed. The cause of the change of absorber tube temperature on absorber emissivity in the LUZ systems was reported by Lippke [4]. The increase of emissivity with temperature has a main cause on collector thermal loss and collector effectiveness. A direct steam generation (DSG) collector has also been proposed as a future generation of the LUZ type trough collector by Cohen and Kearney [5]. This arrangement has the development of eliminate the expensive synthetic oil, intermediate heat transport piping loop and oil to the steam heat exchanger. Fraidenraich et al. [6] developed a closed form solution that enables to estimate the profile of the absorber temperature; fluid temperature and power deliver next to a parabolic linear focus collector. Analytical modeling of a solar power plant with parabolic linear collector was used as a basis for the development of a code implemented by Jones et al. [7] in the TRNSYS thermal simulation software. Quaschning et al. [8] also used a model based on previous works. Price [9] developed a computer model that combines an investigation of the performance of a parabolic trough solar power plant with its cost and economic parameters. The model was able to propose a Rankine cycle parabolic trough plant, with or without thermal storage and fossil fuel support. The best balance between the operational performance and cost of the plant was discussed. Forristall [10] suggested that the thermal losses of collectors are treated with a regression curve obtained from the detailed model and expressed as a utility of the fluid temperature. The different part of the solar power station is treated with great detail, even though, sometimes, it is difficult to find out the exact modeling hypothesis included in the simulation software. 


\section{USEFUl THERMAL ENERGY}

The useful solar energy collected by a solar collector $Q_{u}(t)$ is influenced by three major factors:

- The ability of the absorbing element to absorb the available insolation that is incident on the element after being reflected from or transmitted through other collector components.

- The magnitude of the thermal losses due to convection to the ambient air, and

- The magnitude of thermal losses due to radiative exchange with the surroundings.

The useful solar energy can be expressed mathematically as:

$Q_{u}(t)=q_{u}(t) A_{c}=(\tau \alpha)_{e} q_{s}(t) A_{c}-\bar{U} A_{e}\left(\overline{T_{e}}-T_{a}\right)-\varepsilon_{e} \sigma A_{e}\left(T_{e}^{4}-T_{a}^{4}\right)$

(The usable energy collected $=$ Energy Absorbed-Convective losses-Radiated losses)

In this relation, $(\tau \alpha)_{e}$ is the fraction of the insolation striking the collector aperture that is absorbed by the absorbing element of the collector, and accounts for all losses because of the cover plates, reflectors, lenses or other optical elements in the parabolic collector. The term $q_{s}(t) A_{c}=Q_{s}(t)$ represents the instantaneous insolation per unit of aperture area striking the collector aperture, $q_{s}(t)$ represents the time and the collector aperture area, $A_{c}$.

Thus, the first term on the right of the equation (1) is the solar energy absorbed by the absorbing element of the collector. The second term on the right of the equation (1) represents losses due to convection and conduction from collector in terms of average overall heat-transfer coefficient $\bar{U}$ times the absorbing element area $A_{c}$ times the difference between the average absorber surface temperature $\overline{T_{e}}$ and the ambient temperature $T_{a}$. Both $\overline{T_{e}}$ and $T_{a}$ may be time-dependent. The third term on the right of the equation (1) accounts for the exchange of infrared radiation between the collector and surroundings.

A measure of the collector performance is the ratio of the useful collected energy $Q_{u}(t)$ to the available incident energy $q_{s}(t) A_{c}$ known as collector efficiency $(\eta)$ and expressed mathematically as:

$\eta=\frac{Q_{u}(t)}{q_{s}(t) A_{c}}=(\tau \alpha)_{e}-\left[\left\{1 / q_{s}(t) A_{c}\right\}\left\{\bar{U} A_{c}\left(\bar{T}_{e}-T_{a}\right)-\varepsilon_{e} \sigma A_{e}\left(\bar{T}_{e}^{4}-T_{a}^{4}\right)\right\}\right]$

In dimensional form

$\eta=\frac{Q_{u}(t)}{q_{s}(t) A_{c}}=\left(\tau \alpha_{e}\right)-\frac{1}{\psi(t)}\left[b\left(\theta_{c}-\theta_{a}\right)+\left(\theta_{c}^{4}-\theta_{a}^{4}\right)\right]$

To simplify the analysis, it is desirable to put an equation (3) in terms of dimensionless, fluid inlet temperature $\theta_{f i}=T_{f i} / \overline{T_{a}}$ rather than in terms of the average dimensionless surface temperature $\theta_{e}$. If the relationship of the form

$\frac{F_{R}}{\psi(t)}\left[(\tau \alpha)_{e}-\left\{b\left(\theta_{f i}-\theta_{a}\right)+a\left(\theta_{f i}^{4}-\theta_{a}^{4}\right)\right)\right]=(\tau \alpha)_{e}-\frac{1}{\psi(t)}\left[b\left(\theta_{e}-\theta_{a}\right)+\left(\theta_{e}^{4}-\theta_{a}^{4}\right)\right]$

As assumed, then the equation (3) becomes in dimensional form

$\eta=F_{R}\left[(\tau \alpha)_{e}-\frac{1}{q_{s}(t) A_{c}}\left\{\bar{U} A_{e}\left(\overline{T_{f i}}-T_{a}\right)-\varepsilon_{e} \sigma A_{e}\left(\overline{T_{f i}^{4}}-T_{a}^{4}\right)\right\}\right]$

In dimensionless form

$\eta=F_{R}\left[(\tau \alpha)_{e}-\frac{1}{\psi(t)}\left\{b\left(\theta_{f i}-\theta_{a}\right)+a\left(\theta_{f i}^{4}-\theta_{a}^{4}\right)\right\}\right]$

The $F_{R}$ relates the average collector temperature to the more easily measured fluid inlet temperature, and the collector efficiency can now be found in terms of the fluid inlet temperature.

The net enthalpy gain $Q_{u}(t)$ of the fluid flowing through the collector is given by

$Q_{u}(t)=\delta_{c} m_{c} C_{p}\left(T_{f o}-T_{f i}\right)$

The value of $Q_{u}(t)$ is related to the insolation $q_{s}(t)$ through the definition of collector efficiency by

$Q_{u}(t)=\eta q_{s}(t) A_{c}$ 
and,

$$
\begin{aligned}
& T_{f o}=T_{f i}\left(1-\frac{b F_{R}}{\gamma}\right)+\frac{T F_{R}}{\gamma}\left[\psi(t)(\tau \alpha)_{e}+b \theta_{a}\right]-\left(\frac{a T_{a} F_{R}}{\lambda}\right)\left(\theta_{f i}^{4}-\theta_{a}^{4}\right) \\
& \gamma=\delta_{c} m_{c} T_{a} / q_{\text {sref }} A_{c}
\end{aligned}
$$

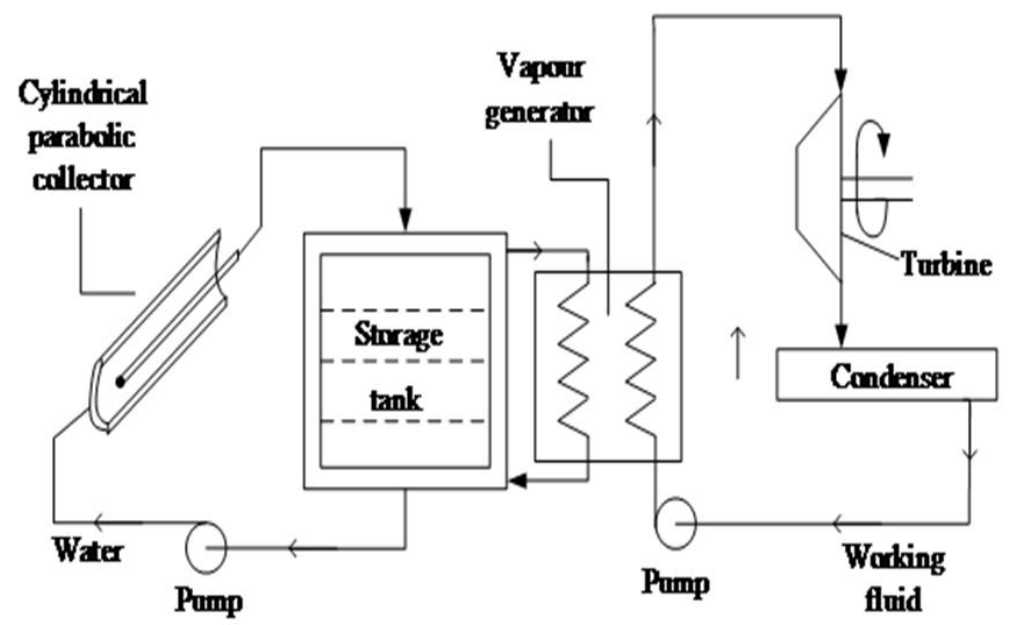

Fig. 1 Block diagram of solar thermal conversion system

As $\gamma$ approaches zero ( $m_{c}$ tends to zero, near stagnation conditions), equation (11) predicts [using equation (9)] that no flow or stagnation temperature of the collector is given by

$$
T_{\text {stag }}=\overline{T_{a}}+\frac{1}{b q_{s, r e f}}(\tau \alpha)_{e} q_{s}(t) \overline{T_{a}}-\frac{1}{b} a \overline{T_{a}}\left(\theta_{\text {stag }}^{4}-\theta_{a}^{4}\right)
$$

also,

$$
T_{\text {stag }}=\overline{T_{a}}+\frac{1}{U A_{e}}(\tau \alpha)_{e} q_{s}(t) A_{c}-\frac{1}{U} \varepsilon_{e} \sigma\left(T_{\text {stag }}^{4}-T_{a}^{4}\right)
$$

It can be written in terms of thermal fluid temperature at the collector entrance $\left(T_{f i}\right)$ and at the collector exit $\left(T_{f o}\right)$ as,

$Q_{u}(t)=Q_{u}=m_{f} C_{p}\left(T_{f o}-T_{f i}\right)$

\section{RESULTS AND DISCUSSIONS}

Thermal performance of parabolic trough collector was predicted on the basis of simulated results using $C++$ program for the system, operating and physical parameters and properties employed like $T_{a}=300 \mathrm{~K}$, $\overline{T_{a}}=300 \mathrm{~K}$ and $\overline{T_{e}}=600 \mathrm{~K}$, overall heat transfer co-efficient, $\bar{U}=0.3$ to $12 \mathrm{~W} / \mathrm{K}-\mathrm{m}^{4}$, transmissivity for solar energy, $\tau$ absorptivity for solar energy, $\alpha$ and $\tau \alpha=0.85$, dimensionless insolation, $\psi(t)=0.2$ to 1 , Stefan Boltzmann Constant, $\sigma=5.67 \times 10^{-11} \mathrm{~kW} /\left(\mathrm{m}^{2}-K^{4}\right)$, Fluid inlet temperature, $T_{f i}=353 K, \varepsilon=0.2$ to 1 , radiative loss parameter varies between 0.001165 to 0.00574 and thermal loss parameter varies between 0.01125 to 0.05625 .

\section{A. Effect of Thermal Loss Parameter on Collector Efficiency}

Fig. 2 shows the efficiency of parabolic trough collectors as a function of dimensionless insolation for a fixed value of the radiative loss parameter and various values of thermal loss parameters. The maximum and minimum values of efficiencies have been found to $78.63 \%$ and $53.16 \%, 77.51 \%$ and $47.54 \%, 76.38 \%$ and $41.91 \%, 75.26 \%$ and $36.29 \%$, and $74.13 \%$ and $30.66 \%$ for thermal loss parameters $0.01125,0.0225,0.03375$, 0.045 and 0.05625 , respectively. 


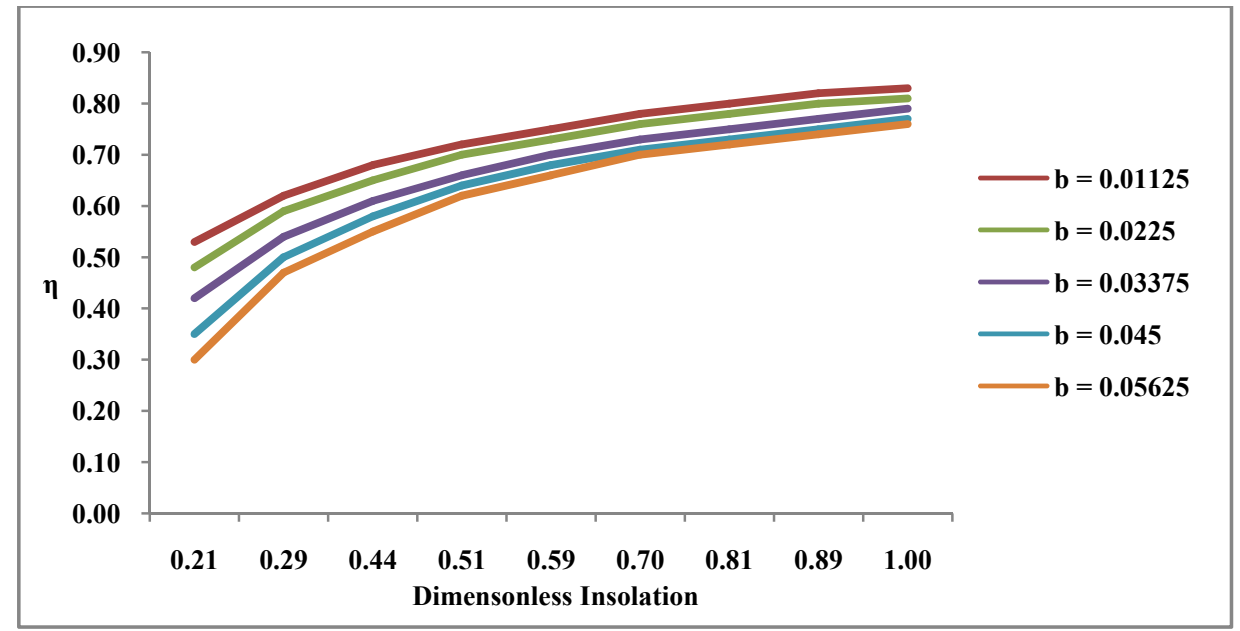

Fig. 2 Efficiency as a function of dimensionless insolation

\section{B. Effect of Radiative Loss Parameter on Collector Efficiency}

Fig. 3 shows the efficiency of parabolic trough collectors as a function of dimensionless insolation for a fixed value of the thermal loss parameter of 0.03375 and various values of radiative loss parameters. The maximum and minimum values of efficiencies have been found to $79.88 \%$ and $59.39 \%, 78.16 \%$ and $50.81 \%, 76.45 \%$ and $42.23 \%, 74.73 \%$ and $33.65 \%$, and $73.25 \%$ and $25.72 \%$ for radiative loss parameters of $0.001165,0.00231$, $0.00345,0.00459$ and 0.00574 , respectively.

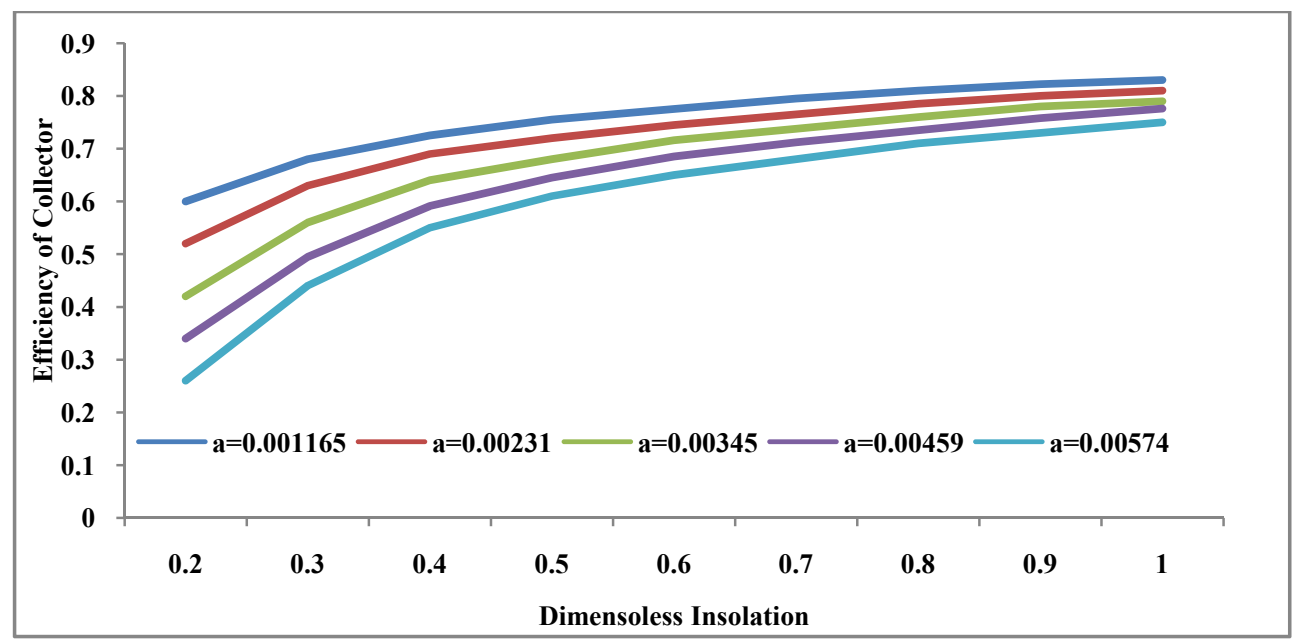

Fig. 3 Effect of radiative loss parameter on collector efficiency

\section{Effect of Thermal Loss Parameter on Heat Removal Factor}

Fig. 4 shows the heat removal factor as a function of dimensionless insolation for a fixed value of the radiative loss parameter of 0.03495 and various values of thermal loss parameters. The minimum and maximum values of heat removal factor have been found to be 0.125 to $0.925,0.112$ to $0.912,0.101$ to $0.898,0.855$ to 0.0886 to 0.886 and 0.0722 to 0.873 for $0.01125,0.0225,0.03375,0.045$ and 0.0562 , respectively. 


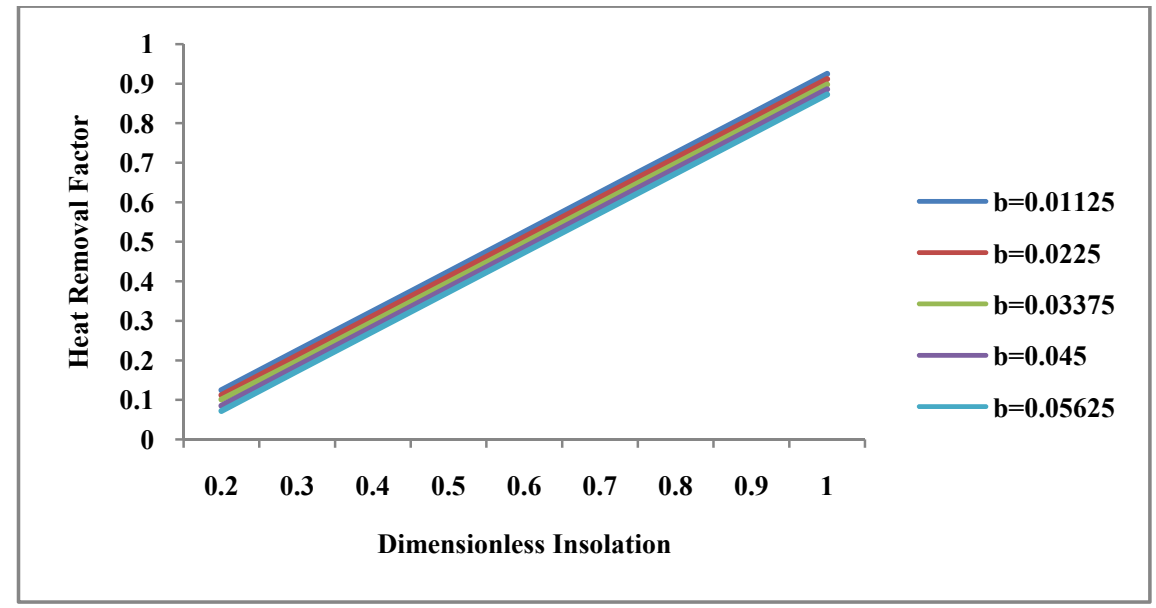

Fig. 4 Effect of thermal loss parameter on heat removal factor as a function of dimensionless insolation

\section{Effect of Radiative Loss Parameter on Heat Removal Factor}

Fig. 5 shows the heat removal factor as a function of dimensionless insolation for a fixed value of the thermal loss parameter of 0.03375 and various values of radiative loss parameters. The minimum and maximum values of heat removal factors have been found to be 0.139 to $0.925,0.119$ to $0.919,0.0987$ to $0.899,0.078$ to 0.879 and 0.058 to 0.858 for relative loss parameters of $0.001165,0.00231,0.00345,0.00459$ and 0.00574 , respectively.

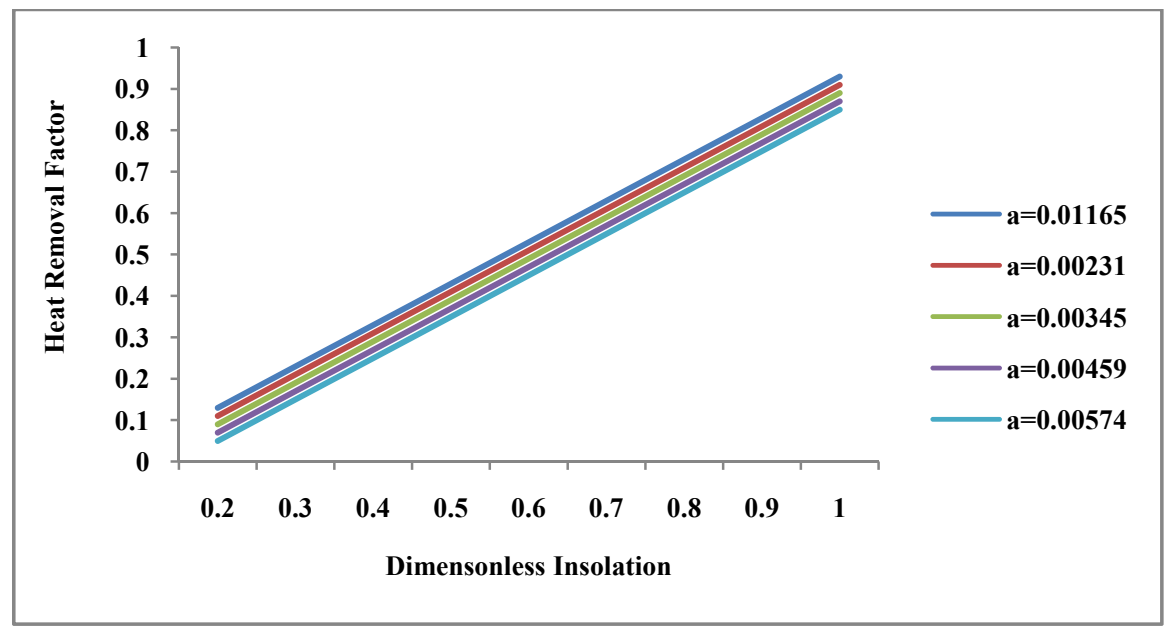

Fig. 5 Effect of radiative loss parameter on heat removal factor as a function of dimensionless insolation

\section{E. Effect ofRadiative Loss Parameter on Fluid Outlet Temperature}

Fig. 6 shows the plot of fluid outlet temperature of parabolic collector as a function of dimensionless insolation for different values of radiative loss parameter and a fixed value of thermal loss parameter, $b=0.03375$. The fluid outlet temperature linearly increases from $350^{\circ} \mathrm{C}$ to $356.87^{\circ} \mathrm{C}$ at $a=0.001165$ and fixed value of $b=0.03375$ and then these values of minimum and maximum temperature are $353.09^{\circ} \mathrm{C}$ to $361.92^{\circ} \mathrm{C}$ at $a=0.00231,355.87^{\circ} \mathrm{C}$ to $370.80^{\circ} \mathrm{C}$ at $a=0.00345,360{ }^{\circ} \mathrm{C}$ to $384.11^{\circ} \mathrm{C}$ at $a=0.00459$ and $363^{\circ} \mathrm{C}$ to $400.11^{\circ} \mathrm{C}$ at $a=0.00574$ respectively. 


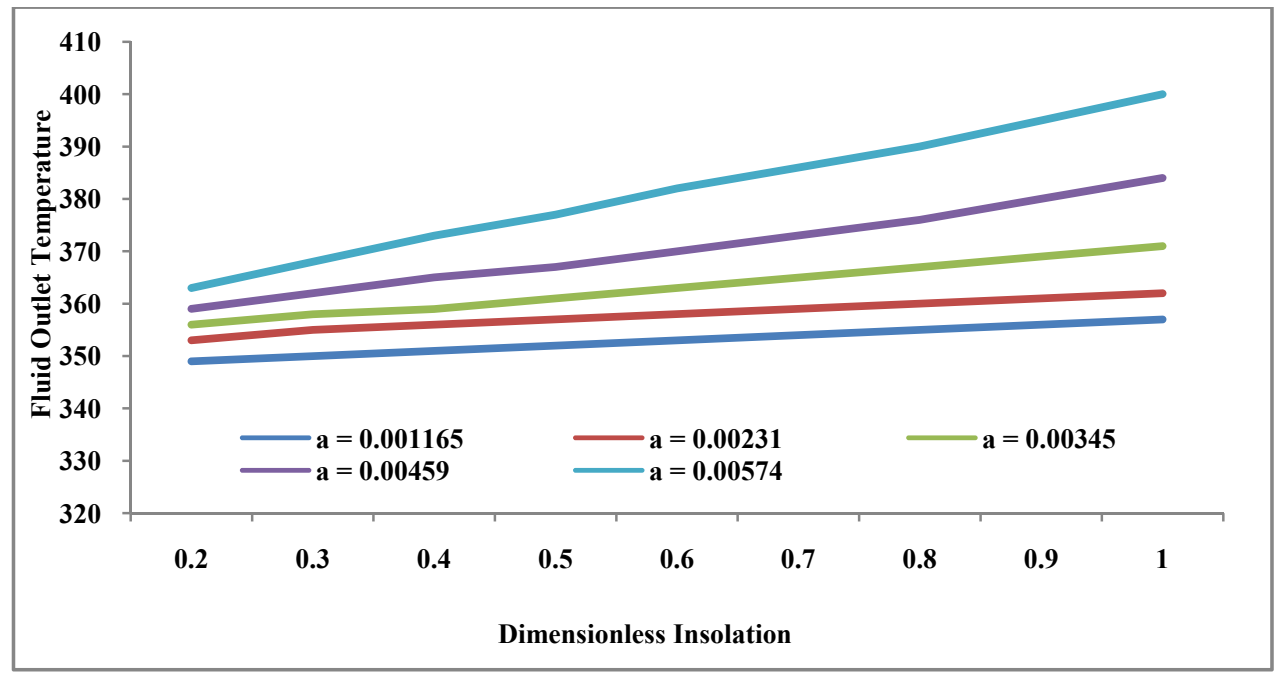

Fig. 6 Effect of radiative loss parameter of the fluid outlet temperature as a function of dimensionless insolation

\section{F. Effect ofThermal Loss Parameter on Fluid Outlet Temperature}

Plots shown in Fig. 7 show that the effect of thermal loss parameter on outlet fluid temperature for a fixed value of relative loss parameter. It has been found that the outlet fluid temperature rises from $345.12^{\circ} \mathrm{C}$ to $384.71^{\circ} \mathrm{C}, 350^{\circ} \mathrm{C}$ to $390.07^{\circ} \mathrm{C}, 355 .{ }^{\circ} \mathrm{C}$ to $394.83^{\circ} \mathrm{C}, 360.69^{\circ} \mathrm{C}$ to $401^{\circ} \mathrm{C}$ and $365.75^{\circ} \mathrm{C}$ to $404.94^{\circ} \mathrm{C}$ for thermal loss parameters of $0.01125,0.0225,0.03375,0.045$ and 0.05625 , respectively.

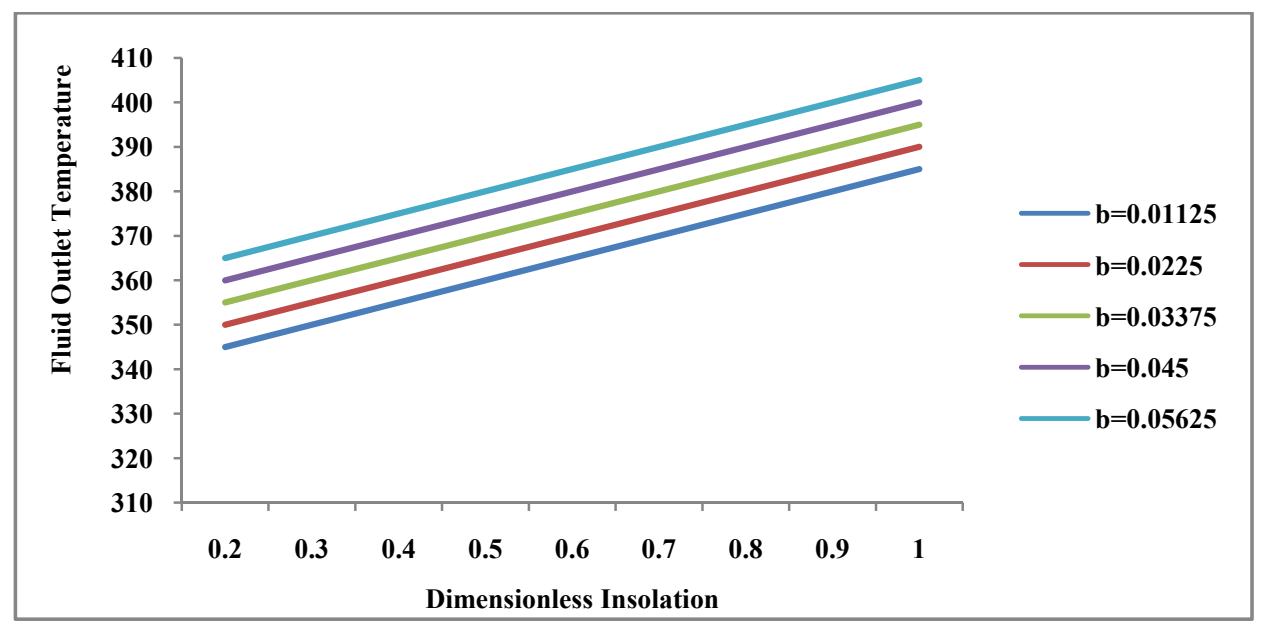

Fig. 7 Effect of thermal loss parameter on the fluid outlet temperature as a function of dimensionless insolation for a $=0.03495$

\section{G. Effect of Mass Flow Rate on Outlet Fluid Temperature}

The plot shown in Fig. 8 shows the outlet fluid temperature as a function of mass flow rate for various values of dimensionless insolation and a fixed value of the radiative loss parameter and thermal loss parameter. The maximum and minimum values of outlet fluid temperature as mass flow rate increases from 0.2 to $1.0 \mathrm{~kg} / \mathrm{s}$ is found to be $360.11^{\circ} \mathrm{C}$ and $341.69^{\circ} \mathrm{C}$ for dimensionless insolation of $0.2, a=0.03495$ and $b=0.03375$ and then these value increases with respect to increase in mass flow rate at higher values dimensionless insolation. The maximum and minimum values are found to be $370.36^{\circ} \mathrm{C}$ and $348.57^{\circ} \mathrm{C}, 377.15^{\circ} \mathrm{C}$ and $353.15^{\circ} \mathrm{C}$, $388.51^{\circ} \mathrm{C}$ and $360.76^{\circ} \mathrm{C}$, and $399.99^{\circ} \mathrm{C}$ and $367.15^{\circ} \mathrm{C}$ for dimensionless insolation of $0.4,0.6,0.8$ and 1.0 , respectively. 


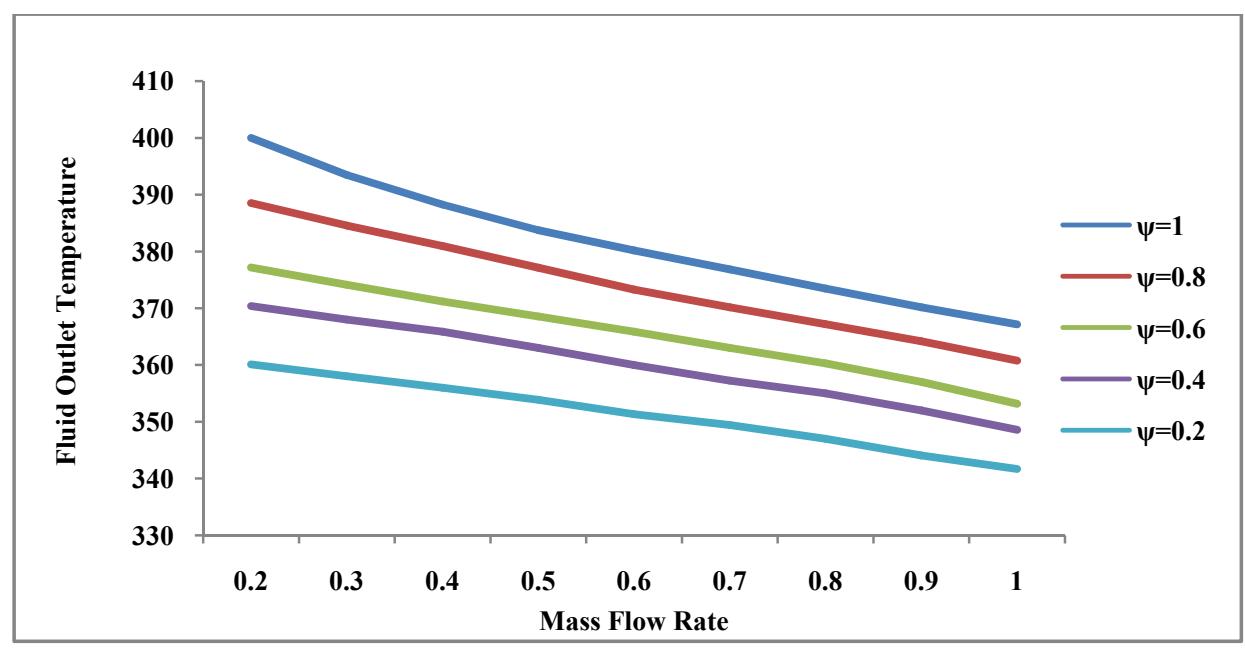

Fig. 8 Effect of dimensionless insolation on fluid outlet temperature as a function of mass flow rate

\section{H. Effect of Thermal Loss Parameter on Rise of Temperature}

Fig. 9 shows that the temperatures rise $(\Delta t)$ as a function of dimensionless insolation for various values of thermal loss parameter and a fixed value of radiative loss parameter. The maximum and minimum values are found to be $374.94^{\circ} \mathrm{C}$ and $334.75^{\circ} \mathrm{C}$ at $b=0.05625$ and then these maximum and minimum temperature rise are $370.14^{\circ} \mathrm{C}$ and $329.69^{\circ} \mathrm{C}$ at $b=0.045,364.83^{\circ} \mathrm{C}$ and $324.63^{\circ} \mathrm{C}$ at $b=0.0375,360.17^{\circ} \mathrm{C}$ and $319.58^{\circ} \mathrm{C}$ at $b=0.0225,354.71^{\circ} \mathrm{C}$ and $314.53^{\circ} \mathrm{C}$ at $b=0.01125$, respectively.

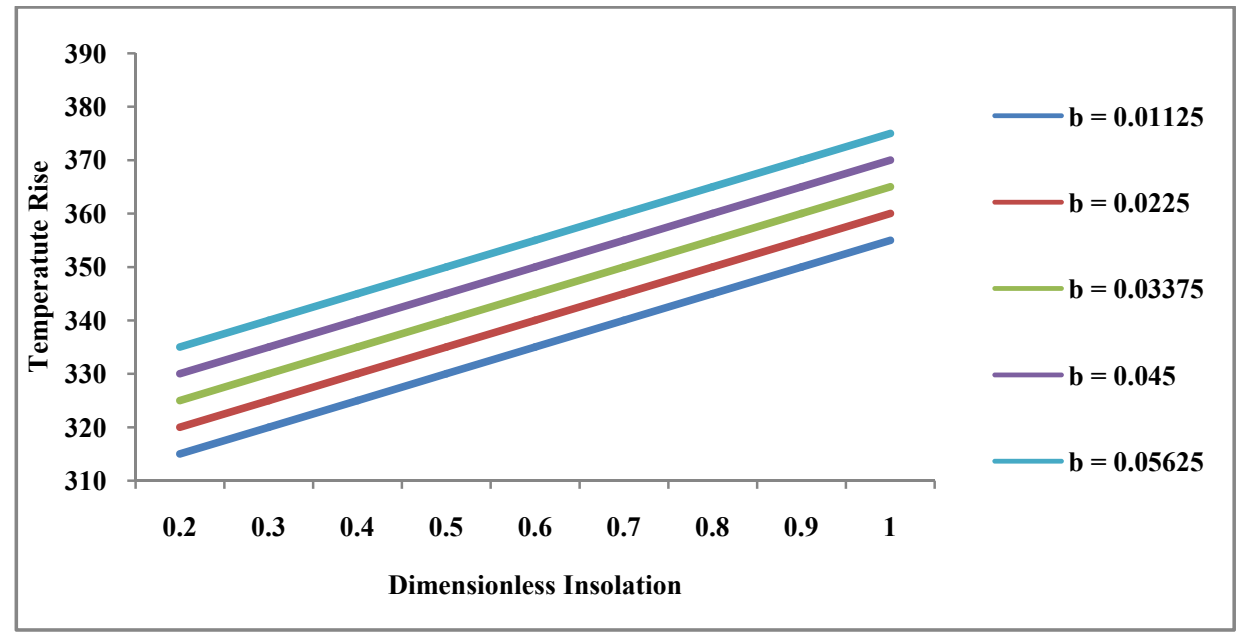

Fig. 9 Effect of thermal loss parameter on rise of temperature as a function of dimensionless insolation

\section{Conclusion}

On the basis of analytical investigations carried out in this work in connection with the mathematical analysis and performance evaluation of parabolic trough collector, the following conclusions are drawn:

1. The mathematical expression for collector efficiency, heat removal factor and outlet fluid temperature have been developed for cylindrical parabolic trough collector through which the working fluid flows.

2. The plots of efficiency as a function of dimensionless insolation $\Psi(t)$ reveal that the efficiency monotonically increases with increase in $\Psi(t)$ for all values of thermal loss parameter ' $b$ ' and increase in ' $b$ ', decrease the efficiencies. The thermal loss parameter, $b=0.01125$ maintains the highest efficiency value throughout the range of dimensionless insolation investigated. Furthermore, a slight fall is observed in the rate of increase of efficiency as $\Psi(t)$. The maximum and minimum efficiency have been found to be $78.63 \%$ and $53.16 \%$ respectively for relative loss parameter equals to 0.01125 .

3. It is also seen that the efficiency increases with increase in dimensionless insolation for all values of radiative loss parameter ' $a$ '. The radiative loss parameter, $a=0.001165$, maintains the highest efficiency throughout the range of $\Psi(t)$ investigated. The increase in the radiative loss parameter ' $a$ ', decrease the efficiency. 
4. The thermal loss parameter and radiative loss parameter also affect the values of the heat removal factor of the cylindrical parabolic trough collector. It has been found that the heat removal factor linearly increases with $\Psi(t)$ for all values of thermal loss parameters. The value of heat removal factor $\left(F_{R}\right)$ changes from 0.125 to 0.925 for $b=0.01125$.

5. The results show that the heat removal factor also increases from 0.13 to 0.93 with an increase in $\Psi(t)$ for $a=0.001165$ and $b=0.03375$. The values of heat removal factor are decreasing with an increase in the radiative loss parameter.

6. The fluid outlet temperature $\left(T_{f o}\right)$ as a function of dimensionless insolation plots show that the outlet fluid temperature increases linearly from $363^{\circ} \mathrm{C}$ to $400^{\circ} \mathrm{C}$ for $a=0.00574$ and $b=0.03375$. The maximum values of fluid outlet temperature are $357^{\circ} \mathrm{C}, 362^{\circ} \mathrm{C}, 371^{\circ} \mathrm{C}$ and $384^{\circ} \mathrm{C}$ for $a=0.001165,0.00231$, 0.00345, 0.00459respectively.

7. It is also seen that the outlet fluid temperature decreases with increase in mass flow rate for all values of $\Psi(t)$. The temperature fall for fixed value of $\Psi(t)$ is seen to be non-linear, the higher values of mass flow rate showing a less steep fall as compared to the lower value of mass flow rate.

8. The maximum and minimum values of outlet fluid temperatures as mass flow rate increases from 0.2 to $0.1 \mathrm{~kg} / \mathrm{s}$ is found to be $360.11^{\circ} \mathrm{C}$ and $341.69^{\circ} \mathrm{C}$ for $\Psi(t)=0.2, a=0.03495$ and $b=0.03375$ and then these values increase with respect to increase in mass flow rate at higher values of $\Psi(t)$. The maximum and minimum values of temperatures are found to be $370.36^{\circ} \mathrm{C}$ and $348.57^{\circ} \mathrm{C}$ for $\Psi(t)=0.4,377.15^{\circ} \mathrm{C}$ and $353.13^{\circ} \mathrm{C}$ for $\Psi(t)=0.6,388.51^{\circ} \mathrm{C}$ and $360.76^{\circ} \mathrm{C}$ for $\Psi(t)=0.8,399.99^{\circ} \mathrm{C}$ and $367.15^{\circ} \mathrm{C}$ for $\Psi(t)=1$, respectively.

To summarize, it can be stated that the performance of solar electric generating systems with parabolic trough collector can be considerably enhanced by modifying the configurations of parabolic trough collector and this enhancement is a strong function of the system and operating parameters. Furthermore, the parametric dependence of thermal performance as discussed above bring out clearly, the need for a judicious choice of the system and operating parameters to obtain the maximum benefit from solar thermal power generating system.

\section{REFERENCES}

[1] San Diego Renewable Energy Group, “Potential for Renewable Energy in the San Diego Region,” August 2005.

[2] M. M. Rolim, N. Fraidenraich, and C. Tiba, “Analytic modeling of a solar power plant with parabolic linear collectors,” Solar Energy, vol. 83, pp. 126-133, 2009.

[3] L. J. Yebra, M. Berenguel, E. Zarza, and S. Dormido, “Object Oriented Modelling and simulation of parabolic trough collectors with MODELICA,”Mathematical \& Computer Modeling of Dynamical Systems, vol. 14, pp. 1-11, August 2008.

[4] F. Lippke, "Direct Steam Generation in the Parabolic Trough Solar Power Plants: Numerical Investigation of the Transients and the control of a Once-Through System,” Journal of Solar Energy Engineering, vol. 118, pp.9-14, 1996.

[5] G. Cohen, and D. Kearney, "Improved Parabolic Trough Solar Electric Systems Based on the SEGS Experience,”Proc. of the Annual Conference of the American Solar Energy Society (Solar 94),June 1994.

[6] N. Fraidenraich,J. M. Gordon, R. C. F. Lima, "Improved Solution for Temperature and Thermal Power Delivery Profile in Linear Solar Collectors,”Solar Energy, vol. 61, pp. 14-145, 1997.

[7] S. A. Jones, N. Blair, R. P. Paal, P. Schwarzboezl, and R. Cable,“TRNSYS Modeling of the SEGS VI Parabolic Trough Solar Electric Generating System,”Proc. of Solar Forum 2001: Solar Energy: The Power to Choose,April 2001.

[8] V. Quaschning, R. Kistner, and W. Ortmanns, "Simulation of Parabolic Trough Power Plants,"in 5th Cologne Solar Symposium, 21 June 2001,p. 46-50.

[9] H. Price, “A Parabolic Trough Solar Power Plant Simulation Model”in International Solar Energy Conference, March 2003.

[10] R. Forristall, "Heat Transfer Analysis and Modeling of a Parabolic Trough Solar Receiver Implemented in Engineering Equation Solver,” National Renewable Energy Laboratory, NREL/TP-550-34169, October 2003.

\section{AUTHOR PROFILE}

Yogesh Kumar Nayak obtained B. E. degree in Electrical \& Electronics Engineering from Pt. Ravi ShankerShukla University, Raipur and M. Tech. degree in Power System from NIT Jamshedpur in year 2008 and 2010 respectively. He worked as an Assistant Professor in the Electrical \& Electronics Engineering Department, CEC, Bilaspur during June-2011 to September-2012. Presently, he is pursuing Ph. D. from NIT Jamshedpur. His main area of research activity is Power System, Renewable Energy and Heat Transfer.

Dr. U. K. Sinha is an Associate Professor in the Electrical \& Electronics Engineering Department, National Institute of Technology,Jamshedpur. He holds a $\mathrm{Ph}$. D. degree in Electrical Engineering and his research interests are in the area is Renewable Energy.

Dr. P. Kumar is an Associate Professor in the Department of Mechanical Engineering, National Institute of Technology, Jamshedpur. He holds a Ph. D. degree in Mechanical Engineering and his research interests are in the areas of Thermal Engineering, Refrigeration \& Air Conditioning. 
Nilesh Kumar obtained B. Tech. degree in Electrical Engineering from Uttar Prdesh Technical University, Lucknow and M. Tech. degree in Power System from NIT Jamshedpur in year 2008 and 2010 respectively. He worked as a Senior Lecturer in the department of Electrical \& Electronics Engineering, BBDNIIT, Lucknow during July-2010 to July-2013. Presently, he is pursuing Ph. D. from NIT Jamshedpur. His research interest includes Power System and Renewable Energy. 